\title{
eJRIEPS
}

Ejournal de la recherche sur l'intervention en éducation physique et sport

$27 \mid 2012$

Varia

\section{Physical Education Futures: Can we reform physical education in the early 21st Century?}

\section{Professor David Kirk}

\section{OpenEdition}

\section{Journals}

Electronic version

URL: http://journals.openedition.org/ejrieps/3222

DOI: ERREUR PDO dans /localdata/www-bin/Core/Core/Db/Db.class.php L.34 : SQLSTATE[HY000]

[2006] MySQL server has gone away

ISSN: 2105-0821

\section{Publisher}

ELLIADD

Electronic reference

Professor David Kirk, « Physical Education Futures: Can we reform physical education in the early 21 st Century? », eJRIEPS [Online], 27 | 2012, Online since 01 July 2012, connection on 20 November 2019. URL : http://journals.openedition.org/ejrieps/3222 ; DOI : ERREUR PDO dans /localdata/www-bin/ Core/Core/Db/Db.class.php L.34 : SQLSTATE[HY000] [2006] MySQL server has gone away

This text was automatically generated on 20 November 2019.

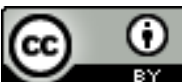

La revue eJRIEPS est mise à disposition selon les termes de la Creative Commons Attribution 4.0 International License. 


\title{
Physical Education Futures: Can we reform physical education in the early 21 st Century? ${ }^{1}$
}

\author{
Professor David Kirk
}

\section{Introduction}

1 There has been a relative lack of interest in futures studies among physical educators. This is somewhat paradoxical, on the one hand, given the colourful and dramatic history of the field in schools and colleges (Fletcher, 1984; Kirk, 1992). On the other, we have seen the rapid development of physical culture, including the commercialisation, commodification and technologisation of sport, exercise and active leisure (Kirk, 1999). Arguably, physical educators lack a historical perspective on their field; they are, effectively, trapped in the present tense. One of the symptoms of being trapped in the present tense is the tendency to be astonished by what appear to be unprecedented developments. And a corollary of being trapped in time is being trapped in social space. To what extent do physical education teachers engage in cultural critique and critical pedagogy? Given the growing gap between rich and poor in developed 'Western' nations and elsewhere over the past 40 years and a range of attendant social problems that are disfiguring these societies, are teachers able to see the 'bigger picture' in which they practice physical education and the contribution they can make to improving the lives of their pupils, particularly those living in poverty?

In this paper I consider whether and to what extent physical education might be considered fit for purpose in the $21^{\text {st }}$ century. In overview, I will ask, does physical education have a future, and relatedly, does physical education have physical cultural legitimacy? I propose a future based on pedagogical models and student-centred physical education. In conclusion, I will ask whether teachers will be likely to participate in the radical reform of their subject. 


\section{Physical education futures: some scenarios}

2 Does physical education have a future? Before we can begin to form a response to this question, we need to decide the period of time we will count as 'the future'. On the one hand, such has been the rate at which 'innovations' have come and gone in physical education during the last decade in England, for example, it is tempting to frame the future in terms of months rather than years. This timeframe is somewhat limiting however if we wish to gain some perspective on and analytical distance from the present. On the other hand, if we frame the future as much longer then twenty years, the speed of technological innovation and the effects of forces as varied as climate change, the economy, the greying population, technology, bioscience, and the so-called obesity crisis, to name just a few, we risk attempting to talk about a world that could be unrecognisable to us.

With these considerations in mind, it might be more acceptable to think in terms of short, middle and longer term futures, with the short term over the next three to five years, the longer term around twenty years, and the middle term somewhere in between. Working with these timeframes, we can perhaps provide some reasonably well-grounded responses to the question 'does physical education have a future?'

If the form of physical education that currently dominates practice (to be discussed next) in many countries around the world remains as it is, my response is that physical education most certainly does have a future in the short term. Through recognition of the importance of physical education to a wide ranging agenda of social 'goods' such as citizenship, health enhancement and obesity reduction, and growing the pool of talented sports people, there should be little to no possibility of physical education's place in the school curriculum being at risk.

In the middle term, however, as increasing scrutiny of and accountability for the use of scarce public resources begins to provide genuine evidence of physical education's current deficiencies, the possibility of a radically different but (for physical educators) unacceptable future may become more likely. Hoffman's (1987) brilliant satire of a commercialised and commodified future for physical education, in which only those who can afford to pay-to-play receive physical education and the rest are merely supervised in unstructured activity time, may be the most likely middle term scenario. While Hoffman's 'impossible dream' wasn't realised within his own timeframe, Tinning's (1992; 2001) successive follow-ups showed that we could well be on our way to this kind of middle term future.

If this middle term future is a strong possibility, then the longer term future indeed looks bleak, at least for the survival of physical education as it is currently understood. But then, when we begin to explore the form of physical education that dominates school practice today and its relevance to the $21^{\text {st }}$ century, we might agree that this longer term future, in which physical education as we know it no longer exists, may be no bad thing.

\section{The relevance of today's physical education to the $21^{\text {st }}$ century}

3 We could respond to this issue with the remark that, far from being relevant to the $21^{\text {st }}$ century, today's physical education has been scarcely relevant for at least the last 30 
years of the $20^{\text {th }}$ century. Between the 1920 s and the 1950 s there was a seismic shift in physical education as it was transformed from a gymnastics-based field of practice to a sports-based field. Due to a complex interplay of forces, ranging from the school timetable and the subject-centred academic curriculum to the sheer number and diversity of physical activities that make up contemporary physical education programmes, a sports-based, multi-activity form of the field emerged, to an extent modified to suit local historical and cultural traditions.

In terms of the day-to-day practice of this form of physical education, we might more accurately speak about physical education-as-sport-techniques. This is because the mainstay of the standard length lesson and short units of work is the teaching and learning of the techniques of a wide range of sports. The term technique rather than skill is appropriate to describe this form of physical education since it is the decontextualised movements of, for example, passing, dribbling and shooting rather than their appropriate, thoughtful application in games and sports that forms the basic stuff of lessons. And since teachers typically work with relatively large groups of 20 or more pupils, within relatively short lessons, and since they are rightly ever-mindful of safety, a directive, command style of teaching predominates. Within this context, all of the research evidence shows that learning progression seldom occurs (eg. Lounsbery and Coker, 2008), and so introductory units of work tend to be taught over and over again (Siedentop, 2002a).

This is the dominant form of physical education in schools currently and has been more or less since the 1960s in the UK and, according to the studies collected in Puhse and Gerber's book (2005), is widespread in many other countries around the world. Despite serious limitations of the subject I have already suggested, physical educators have consistently argued that physical education can provide children and youth with a range of physical, cognitive, affective, social and health benefits (Bailey et al, 2009).

Moreover, preparation for lifelong physical activity is viewed as the subject's raison d'etre. Indeed, physical educators have continued to state this aspiration despite evidence to the contrary, that only a small number are physically active and a much smaller minority continue to play the games and sports that they experienced at school (Kirk, 2002).

This sport-technique-based form of physical education has been spectacularly resistant to change. This resistance to change is not due to a shortage of good ideas (Oslin and Mitchell, 2006). There has in fact been a proliferation of genuinely innovative forms of practice, including Sport Education (Siedentop, 1994; Hastie, 2011), Play Practice (Launder, 2001), Physical Literacy (Whitehead, 2010), Personal and Social Responsibility (Hellison and Martinek, 2006), and Health-Based Physical Education (Haerens et al., 2011).

In the 'West', there has been serious and sustained criticism of physical education-assport techniques with arguably little result in terms of radical change (eg. Almond, 1997; Hoffman, 1987; Lawson, 2009; Locke, 1992; O'Sullivan et al, 1994; Penney and Chandler, 2000).

\section{Physical culture and cultural legitimacy}

4 One way to think about the relevance of the form of school physical education for the $21^{\text {st }}$ century is to consider some of the changes that have occurred within the broader physical culture of society since the 1950s which legitimate (Williams, 1985) physical 
education's place in the curriculum. The field of sport, for example, has become increasingly professionalized, commercialised and commodified. In the 1950s, there were few professional sports, and amateurism retained a stranglehold on sport from beginner to elite levels. Nowadays, in contrast, sport is a big money business, generating billions of pounds of profits for owners, investors and some sportsmen and women. Some sports have changed their rules and formats to suit the televisual media, including cricket, rugby union and field hockey. Billions of pounds more are generated from sports merchandise, including replica sportswear and other paraphernalia.

Despite these radical and far-reaching changes to sport and other forms of physical culture such as exercise and active leisure, school physical education is practiced in much the same way as it was in the 1950s, 60s and 70s. So while the physical cultural forms that provide physical education with much of its public legitimacy have altered in tandem with technological advances, the dominant practice in schools is the teaching and learning of introductory-level sports techniques. In this respect we might argue that this form of physical education is now and has been for some time culturally obsolete. The forms of physical culture that gave physical education-as-sport techniques its cultural legitimacy in the 1950s and 1960s, such as amateurism, have now disappeared.

On the basis of this argument we might reasonably ask what might be done to address this problem. Could any of the good ideas mentioned earlier provide a means of responding to this conundrum of cultural obsolescence and raised expectations to achieve a range of important outcomes?

\section{The role of pedagogical models in the future of physical education}

5 The notion of pedagogical models builds on the ground-breaking work of Jewett, Bain and Ennis (1995) on curriculum models and Metzler (2005) on instructional models. Both authors argue for an approach to physical education that is 'models-based' (Lund and Tannehill, 2005), in which the curriculum or subject matter (physical activity experiences) and teaching strategies are brought into alignment with distinctive learning outcomes to create a design specification for the creation of school and district level programmes.

A good example of a pedagogical model is Sport Education, developed by Daryl Siedentop (1994) and his colleagues during the 1980s and early 1990s. The learning outcomes for Sport Education are the development of competent, literate and enthusiastic sportspersons. In order to achieve these learning outcomes, Siedentop argued that the subject matter of Sport Education is sport, which includes the key features of seasons, record keeping, festivity, a culminating event, persisting groups, and roles in addition to player such as captain, umpire, scorekeeper, equipment officer and so on. Teacher strategies included directive teaching when appropriate, but also more student-centred strategies such peer and reciprocal teaching and problemsolving. Metzler (2005) developed a series of teacher and student benchmarks which can be used to ensure programs designed for specific locales such as individual schools or community sports clubs remain consistent with the key features of the Sport Education model.

A problem with the multi-activity, sport-technique-based ('One Size Fits All') approach 
to physical education is that a wide range of cognitive, affective, health, social and motor skill learning outcomes are pursed using the same programmes, typically involving short units of work, focused on techniques, and utilising predominantly a directive teaching strategy. Since the 1950s, we have traditionally sought to achieve a range of arguably incompatible learning outcomes all through this same approach (Siedentop, 2002b).

In contrast, a models-based approach seeks to retain this range of legitimate learning outcomes for physical education but to align relevant subject matter and teaching strategies with each set of learning outcomes to create a package or a model for programme design. Each model provides a design specification for local versions of physical education programmes that can cater for the specific needs, interests and circumstances of students and teachers, schools and communities. So long as the local versions of physical education are consistent with the teacher and student benchmarks of each model, we can be sure that children are being given opportunities to achieve worthwhile learning outcomes.

A models-based approach could offer middle to long term futures for physical education. There are two main reasons why. First, a models-based approach provides a means for physical education to pursue the wide range of legitimate physical, cognitive and social goals that its proponents have claimed for it for many years (Bailey et al, 2009). Second, by aligning learning outcomes with relevant subject matter and teaching strategies, there is a strong chance that these learning outcomes might be achieved by a majority, if not all, students. In this respect, a critical mass of research on pedagogical models such as Sport Education (Hastie, 2011) and Teaching Games for Understanding (Harvey et al, 2010) has already produced promising results.

While pedagogical models that align learning outcomes, subject matter and teaching strategies might provide the possibility of middle to long term futures for physical education, this innovation in itself may not be enough to ensure a future for the field.

\section{A focus for change: engaging students in physical education}

6 Some physical educators have in the past attempted to establish student-centred forms of physical education, but without any profound or lasting success. Their relative failure is an indication of the power of the teacher-centred multi-activity, sporttechnique-based form of physical education to resist change. But there can be no doubt, as we understand more and more about the social psychology of learning, that the ways in which we seek to engage students in physical education is at least as important, and some would argue more so, as the design of pedagogical models.

There are two key concepts that must guide any efforts to change physical education to meet the challenges of the early to mid- $21^{\text {st }}$ century, perceived competence and motivation. The phenomena they name are closely linked. Goudas and Biddle (1994) found that perceived competence explained over $60 \%$ of variance in internal motivation. While actual competence forms the basis for children's perceptions from age 9 onwards (Nichols, 1989), based both on past experience and others' judgements, young people's perceptions of what they can and cannot do play a critical mediating role in both the level and quality of their engagement in physical activity. Motivation is probably the most studied psychological concept in the physical education literature 
(Lirrg, 2006). A shared conclusion of research is that students are more likely to persist in learning when their motivation to do so derives from an internal rather than an external source.

If the psychologists are correct, then we must consider the pedagogical implications for physical education. It would seem that the traditional approach has not been entirely successful in facilitating internal motivation among generations of students of physical education and, indeed, may have had the opposite effect (Tinning, 2010). One theory suggests that in order to promote internal motivation, young people must be able to fulfil their need for 'autonomy'. In other words, they must feel that they have a genuine say in the form of physical education they experience, that they have real choices that reflect their individual preferences (Van den Berghe et al., in press).

Just how these two concepts of perceived competence and motivation might be applied will depend to a large extent on the form physical education might take. It might be argued that the teacher-centred multi-activity, sport-technique-based form of physical education cannot easily facilitate the development of these key psychological characteristics in young people. Some pedagogical models, such as Sport Education for example, which are explicitly designed for inclusiveness, to reward particular kinds of behaviour, and to offer opportunities for choice and responsibility, might prove more likely to foster perceived competence and motivation.

\section{Conclusion: the role of physical education teachers in the radical reform of physical education}

7 Physical education teachers in post at the end of the first decade of the $21^{\text {st }}$ century are heir to a struggle for recognition and status by their predecessors throughout most of the previous century (Kirk, 1992). Recognition as a core curriculum topic in schools, a very popular examination-based subject in some Anglophone senior secondary school systems, a profession of degree-qualified teachers, opportunities to undertake postgraduate studies, parity of remuneration with teachers of other school subjects, and a thriving research field in the university sector each represent major achievements of physical educators over this period.

In this context, of apparent success, why would physical education teachers as a professional group choose to radically reform their subject? Indeed, since it is widely understood that there remains to be little agreement about the nature and purposes of physical education (Green, 2008) even though there has been genuine progress might suggest it would be risky to do anything more than defend the status quo.

Even though physical education teachers clearly understand that motivation and perceived competence (or in their terms 'enjoyment' and 'self-confidence', Green, 2000) are of central importance to physical education, and even though they might recognise that the currently dominant form of the field does not deliver the benefits it aspires to, there may nevertheless be little taste for radical reform.

Reform is not simply a matter of teachers agreeing to take a models-based approach to physical education. We would also require reform of what Lawson (2009) has described as the 'Industrial-Age school', with its attendant lack of organic connection with many young people's everyday lives.

We would also require the reform of physical education teacher education (PETE). It is clear that we have achieved universal degree level qualifications to teach physical 
education at the expense of our knowledge of the core subject matter of our field, which is physical activity. The challenge here would be to develop what Shulman (1987) describes as teachers' content knowledge alongside their pedagogical content knowledge and still maintain 'degree-worthiness' of PETE programmes.

As if reform of the Industrial Age school and PETE programmes wasn't enough, the radical reform of physical education would also need to account for a range of other challenging developments. For example, in the past 20 to 30 years it has become commonplace for children in many economically advanced countries to have their first experiences of sport in a community rather than a school context.

Meanwhile, the majority of specialist teachers of physical education do not meet these children until they enter secondary schools around ages 11 or 12 . But by the time most children reach secondary schools their perceived competence and motivation and hence their likely engagement in physical activity has already been formed and there is little that physical educators can do to change these dispositions.

Teachers have some very difficult decisions to make about physical education's future. On the one hand, in order to support radical reform of their subject, they could put at risk the substantial achievements of the past 50 to 100 years. On the other hand, if they do not support radical reform, the middle to longer term future of the field looks bleak. Informed opinion within the research community, however, is that the currently dominant form of the subject makes more enemies than friends of children, does not progress their learning and thus fails to develop their perceived competence and motivation for physical activity, and ultimately fails to achieve the ubiquitous aspiration, common to programmes around the world, of a long-term active lifestyle. How long can this state of affairs continue before this truth about physical education in its current form, that it is failing to meet its own aspirations, is finally obvious to the general public?

\section{BIBLIOGRAPHY}

Almond, L. (ed) (1997) Physical Education in Schools, $2^{\text {nd }}$ edn, London: Kogan Page.

Bailey, R., Armour, K., Kirk, D., Jess, M., Pickup, I., Sandford, R. (2009) 'The educational benefits claimed for physical education and school sport: an academic review', Research Papers in Education 24(1), 1-27.

Fletcher, S. (1984) Women First: the female tradition in English physical education 1880-1980, London: Althone.

Goudas, M. and Biddle, S. (1994) 'Perceived motivational climate and intrinsic motivation in school physical education classes', European Journal of Psychology of Education, 9, 237-247.

Green, K. (2000) 'Exploring the everyday "philosophies” of physical education teachers from a sociological perspective', Sport, Education and Society, 5: 109-129.

Green, K. (2008) Understanding Physical Education, London: Sage. 
Haerens, L., Kirk, D., Cardon, G., and Bourdeauhuji, I. (in press) 'The development of a pedagogical model for Health-Based Physical Education', Quest.

Harvey, S., Cushion, C.J., Wegis, H.M. and Massa-Gonzalez, A.D. (2010) ‘Teaching games for understanding in American high-school soccer: a quantitative data analysis using the game performance assessment instrument', Physical Education and Sport Pedagogy, 15, 29-54.

Hastie, P. (2011) 'A review of research on Sport Education: 2004 to the present', Physical Education and Sport Pedagogy, 16

Hellison, D. and Martinek, T. (2006) ‘Social and individual responsibility programs', pp. 610-626 in D. Kirk, D. Macdonald and M. O’Sullivan (eds.) The Handbook of Physical Education, London: Sage.

Hoffman, S.J. (1987) 'Dreaming the impossible dream: the decline and fall of physical education', in J.A. Massengale (ed.) Trends Toward the Future in Physical Education, Champaign, IL.: Human Kinetics.

Jewett, A.E., Bain, L.L., and Ennis, C.D. (1995) The Curriculum Process in Physical Education, (2 ${ }^{\text {nd }}$ ed) Madison: Brown.

Kirk, D. (2010) Physical Education Futures, London: Routledge.

Kirk, D. (2002) 'Quality Physical Education Through Partnerships: A Response to Karel J van Deventer,' Paper presented to the $12^{\text {th }}$ Commonwealth International Sport Conference, Manchester, July.

Kirk, D. (1999) 'Physical culture, physical education and relational analysis', Sport, Education and Society, 4: 63-73.

Kirk, D. (1992) Defining Physical Education: the social construction of a school subject in postwar Britain, London: Falmer.

Launder, A.G. (2001) Play Practice: the games approach to teaching and coaching sport, Champaign: Human Kinetics.

Lawson, H.A. (2009) 'Paradigms, exemplars and social change', Sport, Education and Society, 14: 77-100.

Lirrg, C. (2006) ‘Social psychology and physical education', pp. 141-162 in D. Kirk, D. Macdonald and M. O'Sullivan (eds.) The Handbook of Physical Education, London: Sage.

Locke, L.F. (1992) ‘Changing secondary school physical education', Quest, 44: 361- 372.

Lounsbery, M. and Coker, C. (2008) 'Developing skill-analysis competency in physical education teachers', Quest, 60: 255-267.

Lund, J. and Tannehill, D. (2005). Standards - Based Physical Education Curriculum Development, Sudbury, Mass: Jones and Bartlett Publishers.

Metzler, M.W. (2005). Instructional Models for Physical Education, $2^{\text {nd }}$ edn, Scottsdale, AZ: Holcomb Hathaway.

Nichols, J.G. (1989) The Competitive Ethos and Democratic Education, Cambridge: Harvard University Press.

O'Sullivan, M., Siedentop, D., and Tannehill, D. (1994) 'Breaking out: codependency of high school physical education', Journal of Teaching in Physical Education, 13: 421-428. 
Oslin, J. and Mitchell, S. (2006) 'Game-centred approaches to teaching physical education', pp. 627-651 in D. Kirk, D. Macdonald and M. O'Sullivan (eds.) The Handbook of Physical Education, London: Sage.

Penney, D. and Chandler, T. (2000) 'Physical education: what future(s)?', Sport, Education and Society, 5: 71-87.

Puhse, E. and Gerber, M. (eds) (2005) International Comparison of Physical Education: concepts, problems, prospects, Oxford: Meyer.

Shulman, L. (1987) 'Knowledge and teaching: foundations of the new reform', Harvard Education Review, 57: 1-22

Siedentop, D. (2002a) 'Content knowledge for physical education', Journal of Teaching in Physical Education, 21: 368-377.

Siedentop, D. (2002b) 'Junior sport and the evolution of sport cultures', Journal of Teaching in Physical Education, 21: 392-401.

Siedentop, D. (ed) (1994) Sport Education: quality PE through positive sport experiences, Champaign: Human Kinetics.

Tinning, R. (2010) Pedagogy and Human Movement: theory, practice, research, London: Routledge.

Tinning, R. (2001) 'The 2001 Senate inquiry: a non-preferred scenario for physical education', ACHPER National Journal, 48: 14-16.

Tinning, R. (1992) 'Not so sweet dreams: physical education in the year 2001', ACHPER National Journal, 138: 24-26.

Van den Berghe, L., Vansteenkiste, M., Cardon, G., Haerens, L. (in press) A review of selfdetermination in physical education: overview, research gaps and 3 suggestions from a pedagogical and psychological point of view, Physical Education \& Sport Pedagogy.

Whitehead, M. (2010, ed) Physical Literacy: throughout the lifecourse, London: Routledge.

Williams, E.A. (1985) 'Understanding constraints on innovation in physical education', Journal of Curriculum Studies, 17: 407-413.

\section{NOTES}

1. A version of this paper will be published as Kirk, D. (in press) Physical education for the $21^{\text {st }}$ century, S. Capel and M. Whitehead (eds.) Debates in Physical Education London: Routledge.

\section{ABSTRACTS}

As a possible antidote to being trapped in the present tense, this paper draws on an analysis of the present and the past in order to consider the extent to which physical education in its current form may be fit for the $21^{\text {st }}$ century. I argue that in order to secure middle to longer term futures for some form of physical education in schools, we need radical reform. I offer a models- 
based approach to physical education that is student-centred, inclusive and motivating as key factors to securing a future. I note that teachers have some difficult decisions to make in terms of risking hard-won achievements for their subject by engaging in radical reform, while failure to reform may lead to demise in the longer term.

INDEX

Keywords: PE, sport techniques, physical culture, cultural legitimacy, learning outcomes, models-based approach

\section{AUTHOR}

\section{PROFESSOR DAVID KIRK}

Alexander Chair in Physical Education and Sport, University of Bedfordshire 